Giant-cells" differ from multinucleated myelocytes by the arrangement of their nuclei, which are generally oval, more numerous and grouped symmetrically round the periphery of the cell, while the nuclei of myelocytes are generally round, fewer in number and crowded together in the centre. They are rarely met with in discharge unless the tuberculous process is in a state of acute exacerbation and rapidly breaking down owing to : supplemental infection. In scrapings taken directly from the diseased spot and ground up with normal saline solution they constitute a striking feature in the film when stained with thionin and eosin.

(To be continued.)

\title{
SOME REMARKS ON KERATOSIS LARYNGIS CIRCUMSCRIPTA, WITH NOTES ON A CASE.
}

\author{
By W. G. Porter, M.B., B.Sc., F.R.C.S.ED., \\ Surgeon to the Eye, Ear, and Throat Infirmary, Edinburgh.
}

Keratosis of the larynx is a condition of such extreme rarity that it is desirable to record any example of this disease which may come under observation.

Cass.-The patient, C. M-, at. 23, tailoress, presented herself at the Ear and Throat Infirmary complaining of hoarseness. The condition had lasted for six months, had come on gradually, and was not associated with any other symptom. The hoarseness varied in degree, and increased very considerably when the roict was used to any extent.

The patient was a well-built young woman of healthy appearance. The nose, naso-pharynx, and pharynx showed no morbid appearances. On examination of the larynx the anterior two thirds of the left vocal cord appeared to be covered by a greyishwhite membrane, the surface of which was somewhat crinkled. It projected slightly beyond the free edge of the cord, and externally was lost to view within the sinus of Morgagni. On phonation the cords moved freely, but did not adduct perfectly, there being a slight degree of elliptical paresis; it was thought, however, that this was partly to be accounted for by the mechanical interference of the membrane. The right and the exposed portion of the left cord were slightly congested; the remainder of the larynx appeared healthy. 

JOURXAL OF LARYNGOLOGY, RHINOLOGY, ANI OTOLOQY

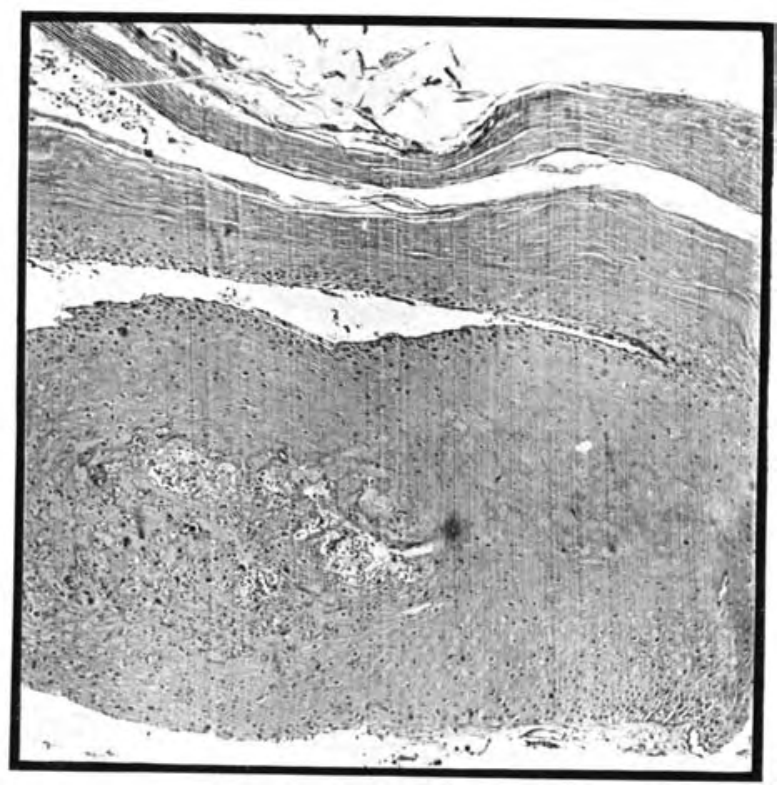

$\times 60$, liam.

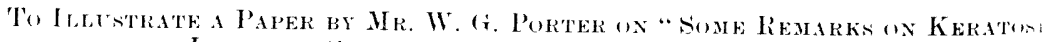

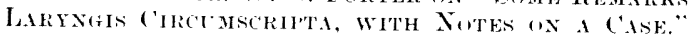


On first examination this apparent membrane was taken to be dried secretion, possibly due to a limited laryngitis sicca, but anainst this was the fact that the patient had never coughed up any particles, nor could she by any forced coughing even after inhalations of steam succeed in getting rid of the supposed secretion. After further observation extending over a fortnight, during which no change took place in the condition, it occurred to me that it might be a case of keratosis, and this view proved to be correct on microscopic examination.

1 removed the greater part of the tissue with forceps under cocaine anæsthesia. It is worthy of note that after seizing the tissue a very distinct tug had to be given in order to withdraw the forceps, and that, althongh there was no blood on the latter, the cord showed a hamorrhagic stain on the surface when examined immediately after the manipulation. This showed that the tissue was intimately connected with the cord itself. The fragments were imbedded in paraffin, and after cutting, the sections were stained with hæmatin and picrofuchsin. They showed towards the surtace a layer of cornified epithelial cells appearing as long fibres, stained yellow, some of which were broken and curled up. Below this was a thick layer of more columnar shaped and squamous epithelial cells, some of which were becoming cornified. This is well seen in the accompanying micro-photograph made from one of my sections by Mr. Richard Muir.

The removal of this tissue combined with voice rest and inhalations of menthol had a very beneficial effect, and four weeks later the hoarseness had completely disappeared. 'There was no return of the keratosis.

Remarks.-I have been able to find in the literature only seven examples of this interesting condition reported by Juffinger, $O$. Chiari, Fein (two cases), Logan 'Turner, Henke, and Baumgarten, Juffinger being the first to describe and name the disease. For the sake of comparison I tabulate these observations below.

It will be seen by glancing at the table that either sex may be affected and that the disease has a wide age distribution-thirteen to sixty-six -in the recorded cases. The onset is slow-six weeks to seven years, - and only one symptom-hoarseness-was complained of by the majority of the patients. In one case (Logan 'Turner) pain was also present, while in Fein's second case breathlessness and cough were prominent. 'The patient in the latter, however, was stated to have a "catarrh" of the right apex, which may explain the last two symptoms. 
The appearances observed are usually of a patch or of patches, chalky or snowy white in colour, with a rough surface frequently presenting a number of fine spicules. They are generally situated on one or both cords, and are then sometimes comparable to a pseudo membrane such as is seen after the use of the cautery (Fein). They occasionally also appeared as rounded swellings below the cord (Juffinger, O. Chiari). In one case the colour was stated to be greenish-white (Turner), while in my own case it was rather a greyish-white, and had exactly the appearance of dried secretion. In no case was there keratosis present in the pharynx. The microscopic appearances were similar in all the cases, and have been described above.

Treatment seems to have been of value in those cases where the overgrowth had been mechanically removed. This would appear to be the most rational method to adopt when the affected area is sufficiently small to make it practicable. In Chiari's and my own case no return was observed after removal, though in the latter it was too recently carried out to permit of an absolute statement to that effect. Chiari mentions that his patient used inhalations of salt solution for a long time, while my patient employed inhalatious of menthol combined with voice rest. In Fein's first case there was a return on two occasions, and he finally obtained a cure by painting the parts with a 10 per cent. alcoholic solution of salicylic acid. He had no returus in his second case, in which he commenced this treatment immediately after removal. Baumgarten also used similar measures with success.

'There are not sufficient data to enable us to draw any conclusions as to the ætiology of this affection.

I must finally mention a case illustrated by $\mathrm{Krieg}^{1}$ in his atlas which very closely resembles the description given of certain of the published cases of keratosis, but which Krieg has named verrucosit dura of the left vocal cord. The patient was a male, at. 60, who complained of hoarseness of a year's duration, and of slight breathlessness. In the larynx a chalky white mass with sharp projections on it was seen on the left vocal cord. The patient died two years after he first came under observation, and at the sectio the right ventricle of Morgagni was found to be filled with a crumbly yellow mass adherent to the surface of the cord; the mass consisted of horny epithelium. On its removal the cord was seen to be eroded, and on microscopic examination there was found a round-celled infiltration, while the very exuberant mucosa was formed of high

1 Krieg, “Atlas der Kehlkopfkrankheiten,” Stuttgart, 1892. 


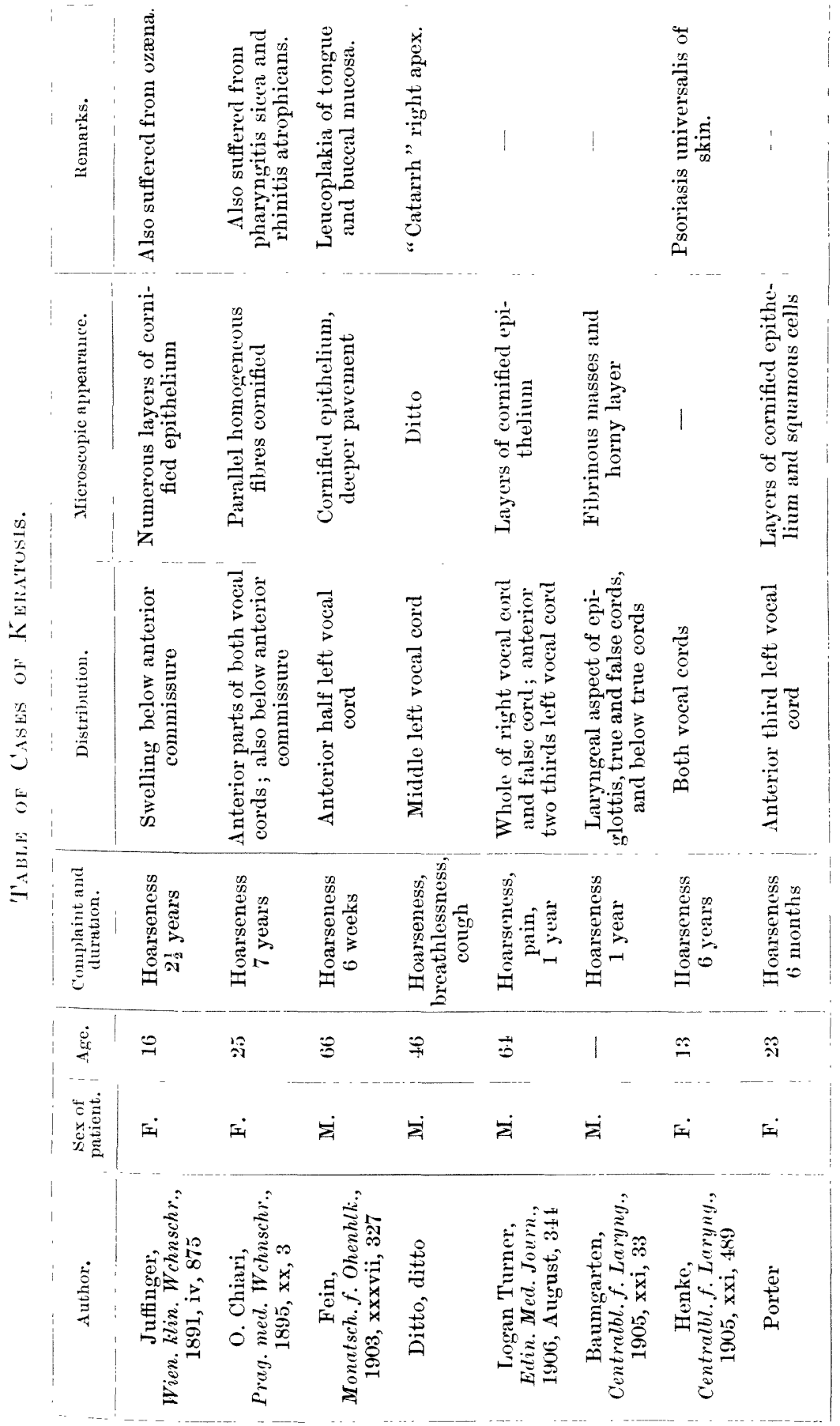


papilla closely packed together, whose epithelial covering had become cornified; one place in the middle of the cord showed it commencing atypical formation of epithelium.

This case, if it was an example of keratosis, is of special importance as being the only one in which a complete microscopic examination has been made. I have very little doubt that it should be classified among the cases of keratosis, and it is more than likely from the date of its publication-1892-that Krieg did not know of Juffinger's paper.

\section{SOCIETIES' PROCEEDINGS.}

\section{PROCEEDINGS OF THE ROYAL SOCIETY OF MEDICINE-LARYNGOLOGICAL SECTION.}

Seventh Ordinary Meeting, May 1, 1908.

J. B. Ball, M.D., President, in the Chair.

Alstract of Proceedings: ly Dr. Dan McKenzie.

Tне following cases and specimens were exhibited:

Śtereoscoptc Photographs of Patrents Operated on by Variots

Methods for Frontal Sinus Disease, Including one to SHOW the EFfect of the Injection of Paraffin for 'THE Purpose of Remedying the Resulting Deformity.

BY Dr. W. S. SYME.

Specimens hrom Cases of Sarcoma and Cases Simulating Sarcoma in the Upper Air-passages.

By Dr. Jobson HoRne.

(1) A section of a growth from the outer side of the nose, and near the inner canthus of the eye, reported to be histologically at fibro-sarcoma. After removal there was no recurrence of the growth, and the case was clinically an innocent tumour. 